\title{
The Tips and Pitfalls of Meniscus Allograft Transplantation
}

\author{
Sung Rak Lee, MD, Jin Goo Kim, MD, PhD and Sang Wook Nam, MD \\ Department of Orthopedic Surgery, Seoul Paik Hospital, Inje University College of Medicine, Seoul, Korea
}

When faced with an irrepairable meniscus or a patient who has had a total or subtotal meniscectomy, meniscus allograft transplantation (MAT) is the preferred modality to restore biomechanical function of the meniscus. The indications for meniscus allograft transplantation are yet to be established. However, currently, MAT has previously been indicated for symptomatic patients who have mild or early osteoarthritis, are younger than 50 years of age, and present with an Outerbridge grade II or lower. The short- to intermediate- term results confirmed noteworthy clinical improvements and consistent objective findings. On the other hand, the successful outcome would be reduced by various complications. Therefore, long-term observation required to evaluate the longevity of these results. The purpose of this article is to review the current research of concerns on the results of MAT, and to describe the technical tips and pitfalls so as to successful clinical results.

Key words: Knee, Meniscus, Meniscus allograft transplantation.

\section{Introduction}

Menisci are responsible for load transmission across the knee, articular cartilage stress reduction by increasing the contact area across the joint, shock absorption, joint stability, joint lubrication, and nutrition of the chondrocytes ${ }^{1-5)}$. Thus, a meniscal tear results in increased stress on the knee joint and reduced contract surface between the tibia and femur, which leads to articular cartilage damage and arthrosis ${ }^{6,7)}$. For the treatment of meniscal tears ${ }^{8,9)}$, meniscal repair is preferred over meniscectomy, and partial meniscectomy is recommended instead of total removal of the meniscus ${ }^{10)}$. Unfortunately, meniscal repair or partial meniscectomy cannot be a viable option for some types of tears. Subtotal or total meniscectomy is unavoidable for the knees

Received December 4, 2011; Revised May 4, 2012; Accepted July 2, 2012. Correspondence to: Jin Goo Kim, MD, PhD.

Department of Orthopedic Surgery, Seoul Paik Hospital, Inje University College of Medicine, 9 Mareunnae-ro, Jung-gu, Seoul 100-032, Korea. Tel: +82-2-2270-0028, Fax: +82-2-2270-0023

Email: boram107@hanmail.net

This is an Open Access article distributed under the terms of the Creative Commons Attribution Non-Commercial License (http://creativecommons.org/licenses/by-nc/3.0/) which permits unrestricted non-commercial use, distribution, and reproduction in any medium, provided the original work is properly cited. with severe degenerative changes or radial tears that extend to the joint capsule. Since first introduced by Milachowski et al. ${ }^{11)}$ in 1989, meniscus allograft transplantation (MAT) has been the subject of many studies ${ }^{12)}$ and widely performed for pain relief and functional improvement. However, a variety of methods have been employed without a proper establishment of techniques ${ }^{13-15)}$. The purpose of this article is to review the outcomes of MAT and describe technical tips for successful transplantation and possible pitfalls.

\section{Meniscus Transplantation}

\section{Indications}

The indications for MAT remain controversial. The most common candidates for the procedure are those who are $\geq 20$ and $<50$ years of age with previous meniscectomy, have no severe degenerative changes and joint instability, present with local pain or swelling in the meniscus-deficient compartment, and show normal lower limb alignment ${ }^{16-18)}$. Meniscus transplantation has been known to produce unsatisfactory results in the knees with advanced arthrosis, and hence, the procedure has been recommended in patients with Outerbridge grade I-II cartilage damage ${ }^{12,19,20)}$. On the other hand, some recent studies reported that the procedure resulted in clinical and functional improvement when performed on carefully selected patients with Outerbridge grade III-IV cartilage damage $e^{21-24)}$ and in 
combination with other procedures for cartilage injury ${ }^{12,25,26)}$.

In addition to the articular cartilage condition, lower limb alignment and ligament stability should also be taken into consideration for MAT. This is because malalignment and ligament instability can be the cause of early failure of the procedure $^{19,21)}$. Staged or concomitant malalignment correction or ligament reconstruction procedures may be necessary ${ }^{17,27)}$. On the other hand, the efficacy of prophylactic meniscus transplantation in combination with meniscectomy has yet to be determined $^{28)}$.

Domestically, meniscus transplantation is performed according to the conditions set by the Health Insurance Review \& assessment (Table 1), which we believe needs to be changed in order to be less restrictive in line with the abovementioned indications with regard to the age criterion.

\section{Contraindications}

The most common contraindications for MAT include advanced degenerative changes of the cartilage (Outerbridge grade III-IV) and radiographic evidence of osteophytes. Joint space narrowing and flattening of the femoral condyle ${ }^{17,29)}$ have also been associated with poor transplantation results. In the presence of lower limb malalignment, undue pressure on the knee may result in graft loosening, degeneration, or tear of the graft $^{23,30)}$. Therefore, a severe varus or valgus deformity should be managed with a staged or concomitant corrective osteotomy. Other indications include obesity (body mass index $>35)^{31}$, skeletal immaturity, knee joint instability, synovial disease, inflammatory arthritis, knee joint infections, asymptomatic conditions, and symptoms irrelevant to meniscal defect ${ }^{28,32)}$.

\section{Graft Type and Treatment}

Meniscus allografts can be cryopreserved, fresh-frozen or deep frozen, fresh, or lyophilized or freeze-dried. Fresh frozen or deep frozen grafts, despite low cell viability, have been most commonly used because of relatively high success rates, low disease transmission risks due to reduced immunogenicity of histocompatible antigens of the grafts, and maintenance of biomechanical properties ${ }^{11,16,33)}$. Ethylene oxide gas sterilization can cause synovitis ${ }^{34)}$. Non-irradiated grafts are more frequently used than the irradiated, since a dose of $2.5-\mathrm{mrad}$ gamma irradiation, which is used for inactivation of human immunodeficiency virus, can cause significant changes in the biomechanical properties of the grafts ${ }^{35)}$.

\section{Graft Sizing}

Appropriate graft sizing is crucial to promote tissue healing and restore chondroprotective role of the meniscus. Graft size can be determined using a plain radiography, magnetic resonance imaging (MRI), or computed tomography (CT). Currently, the graft sizing method suggested by Pollard et al. ${ }^{36)}$ is most widely used. Graft width is determined as the distance from the peak of the tibial eminence to the tibial metaphyseal margin on the anteroposterior (AP) radiograph. Lateral meniscus graft length is

Table 1. Meniscus Transplantation Reimbursement Guidelines

Ja 82-2. Reimbursement for meniscus transplantation will be made when performed under the following conditions. Otherwise, patients will be responsible for the full cost of operation and treatment materials.

A. Age: $20-45$ yr

B. Indications

Patients with knee pain or possibility of aggressive degeneration that is unlikely to resolve with conservative treatment after subtotal or total meniscectomy of the medial or lateral meniscus that can be confirmed with magnetic resonance imaging or arthroscopy and the following conditions.

1) Cartilage condition

Outerbridge grade I-II cartilage damage with no degeneration

2) Periarticular structures

Normal knee alignment and ligament laxity

In case of abnormal knee alignment or ligament laxity, staged or concomitant ligament reconstruction procedure precedes transplantation

3) Conservative treatment period

The conservative treatment period in principle starts 1 year after subtotal or total meniscectomy for the medial meniscus and 6 months after the procedure for the lateral meniscus (early start is possible depending on the doctor's medical opinion)

C. Time: one time per knee (medial or lateral)

Effective 2008.2.1 

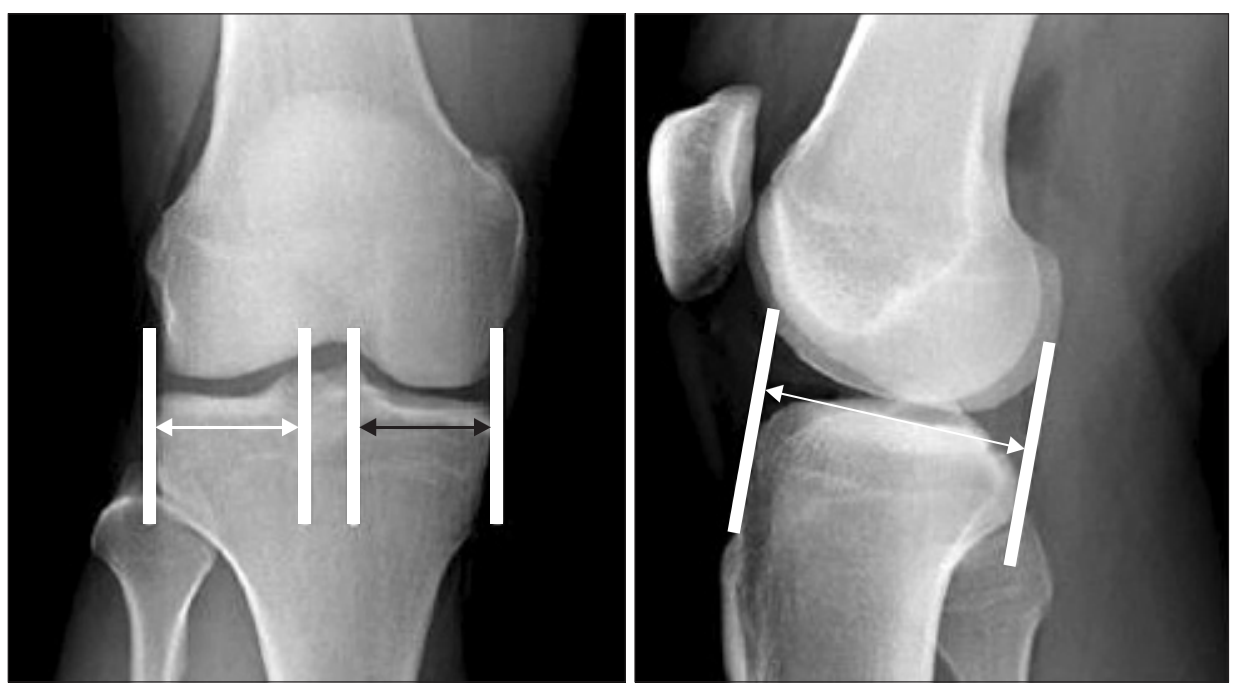

Fig. 1. This anteroposterior radiograph was used to measure the width of meniscus. Width is measured from the peak of medial or lateral tibial eminecnce to its respective tibial metaphyseal margin at the level of the plateau. The lateral radiograph allows for determination of meniscal length. Medial meniscal length is $80 \%$ of the sagittal tibial plateau distance measured at the joint line between a line parallel to the anterior tibia above the tuberosity and one tangent to the posterior plateau margin perpendicular to the joint line. Lateral meniscus length is $70 \%$ of the sagittal tibial distance depicted $^{36,37)}$.

determined as $70 \%$ and medial meniscus graft length as $80 \%$ of the sagittal length of the tibial plateau, which is measured on the lateral radiograph (Fig. 1). Approximately $7-10 \%$ of errors in graft sizing can be acceptable according to Wilcox et al. ${ }^{38)}$ and Dienst et al. ${ }^{39)}$, whereas $5 \%$ can be tolerable according to McDermott et al. ${ }^{40)}$. In our previous study, we reduced the graft size that was measured according to the Pollard's method by $5 \%$ to minimize the meniscal extrusion and achieved successful clinical results without complications ${ }^{41)}$.

\section{Surgical Techniques}

MAT can be performed with either an open or arthroscopic approach, but the latter is more widely used recently ${ }^{12)}$. Regarding the graft fixation method, fixation of soft tissue in conjunction with bone plugs attached to the anterior and posterior horns can be more effective than the soft tissue fixation alone in obtaining rigid fixation and restoring close to normal contact mechanics ${ }^{42}$. However, proper placement of the anterior and posterior horn fixation sites is more important than the surgical technique or fixation method.

The anterior and posterior horns of the medial meniscus are more widely separated than those of the lateral meniscus, and have tibial insertion of the anterior cruciate ligament (ACL) between them. Due to these anatomical differences, the surgical techniques for the two menisci are slightly different as well. In bone plug technique, bone plugs that are attached at the anterior and posterior horns of a graft are placed into the bone tunnels in the tibial plateau. In bone bridge technique, a bone bridge that connects the anterior and posterior horns of a graft is implanted into a trough created on the tibial plateau. The former technique can be performed less invasively without compromising the tibial eminence, but technically demanding. The latter is easy to perform and effective for anatomical restoration, but necessitates more bone resection and removal of tibial eminence. Bone bridge technique is more commonly used for the lateral meniscal tears, whereas bone plug technique is for the medial meniscal tears.

We prefer a modified bone plug technique ${ }^{43)}$ for the medial MAT and keyhole technique ${ }^{38)}$ for the lateral MAT. The modified bone plug technique ${ }^{43)}$ provides excellent fixation strength of the bone plug technique, which permits an easy passage of the graft without creating an additional bone tunnel as with soft tissue fixation. An arthroscopic examination is performed with tourniquet released. Taking care to keep the meniscotibial ligament intact, the remnant meniscus is removed until exposing vascular edge with 1-2 $\mathrm{mm}$ of the outer rim. A fresh frozen or deep frozen graft is thawed in saline solution and excess tissue is removed. For medial MAT, the graft attached to the posterior bone plug ( $8 \mathrm{~mm}$ in width and $2 \mathrm{~mm}$ in length) and the anterior bone plug ( $8 \mathrm{~mm}$, both in width and length) is sutured with Ethibond sutures using a baseball stitch. For lateral meniscus transplantation, a graft with a $10-\mathrm{mm}$ wide bone bridge that connects the anterior and posterior horns is used (Fig. 2).

1) Medial meniscus transplantation using a modified bone plug technique

After diagnostic arthroscopy, the remnant meniscus is resected leaving 1-2 $\mathrm{mm}$ of the meniscal capsular rim. A $10 \mathrm{~mm}$ hole is created using a curette in the posterior root of the medial meniscus for an insertion of the posterior bone shell of the graft (Fig. 3A). A medial collateral ligament release is performed for easy passage of the graft and surgical equipment. The posteromedial aspect of the knee is resected for ligation around 

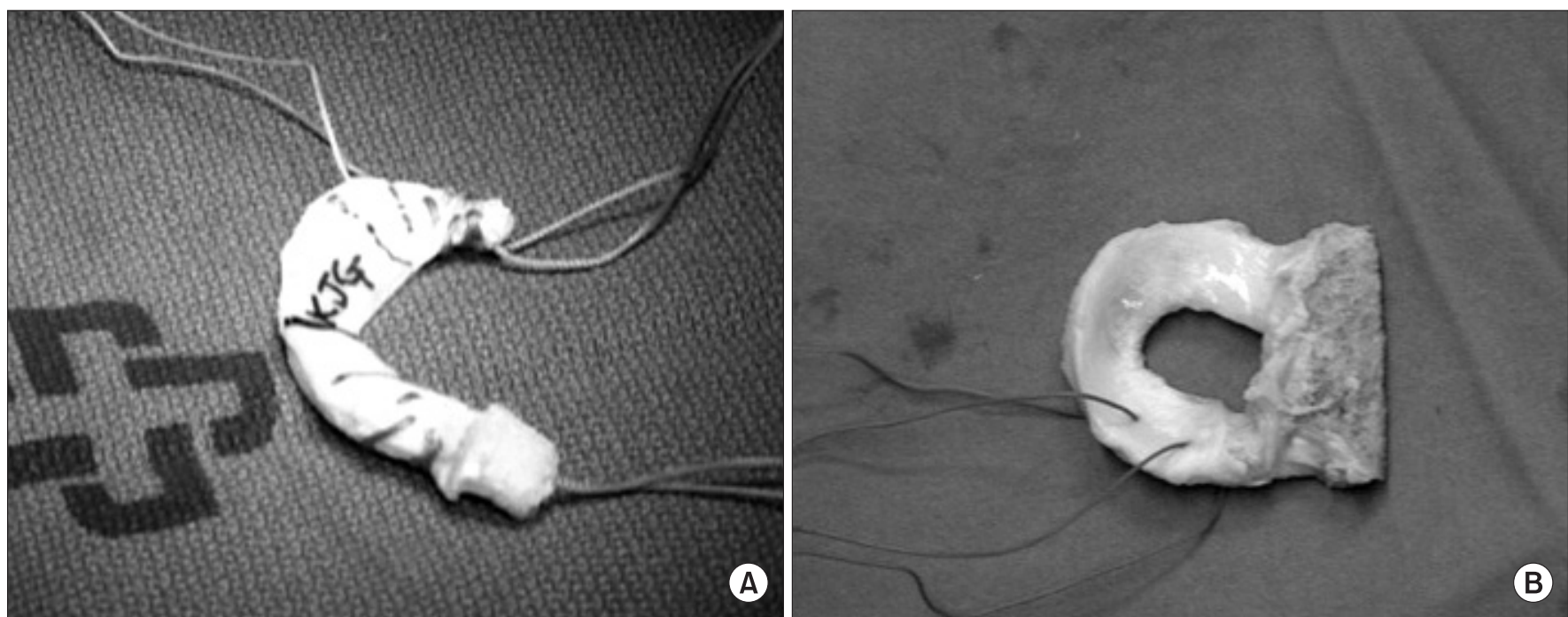

Fig. 2. The prepared fresh-frozen medial meniscal allograft by modified bone plug technique (A), lateral meniscal allograft by key-hole technique (B).
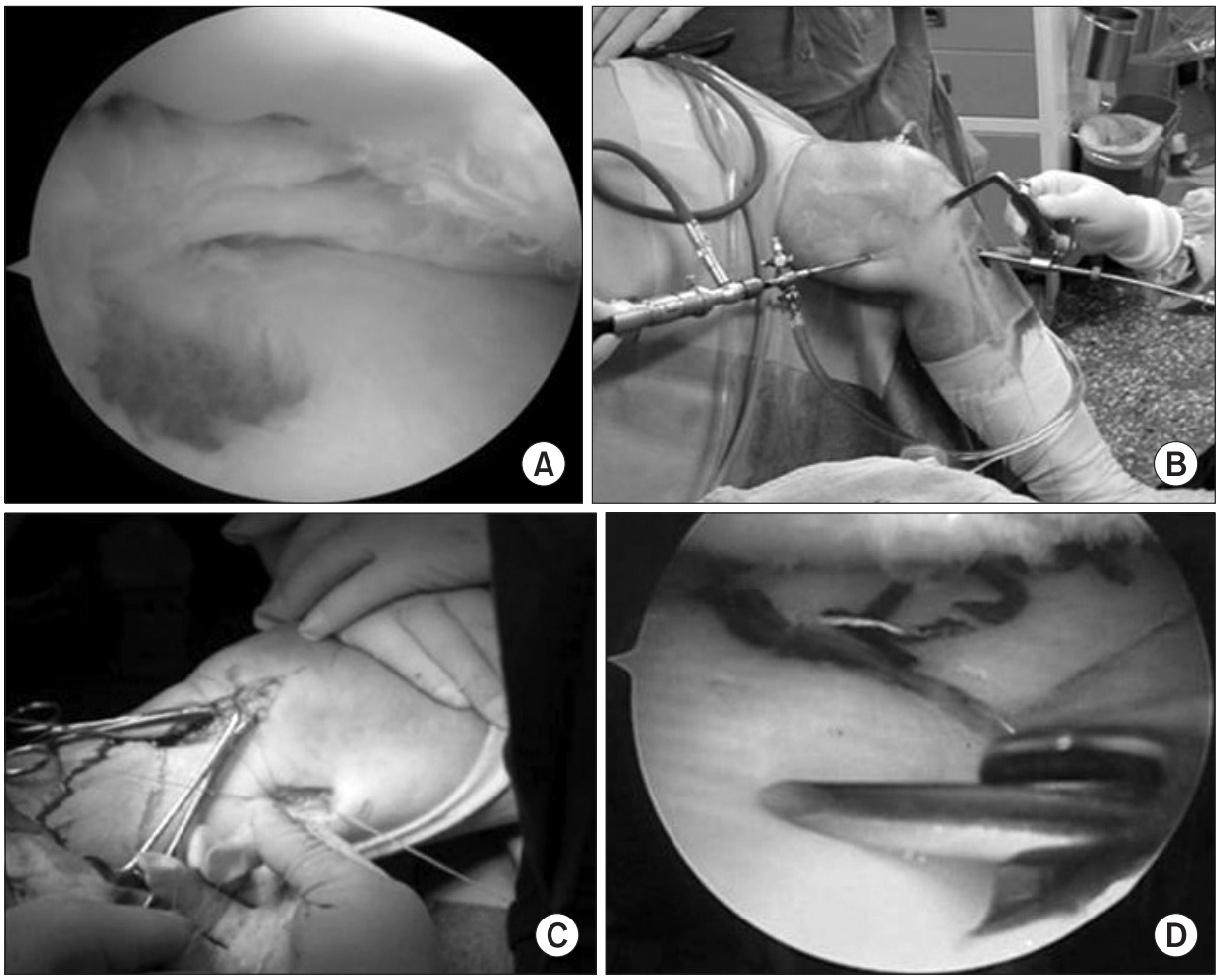

Fig. 3. (A) Preparation of the posterior root area via AM portal by curette. (B) Insertion of the guide pin to posterior root area. (C) Close the arthrotomy site with pulling the leading suture. (D) Meniscus repair by inside-out technique (oblique loop suture).

the joint capsule. A guide pin tunnel is created using an ACL drill guide for passage of the suture attached to the bone shell and a wire for suture passage is inserted through this tunnel (Fig. 3B). Through an anteromedial portal, two wires for leading sutures are passed posteromedially, and an arthrotomy is performed on the anterior knee. The place for bone plug at the anterior horn is created in the tibial plateau using a $10 \mathrm{~mm}$ reamer. After drilling, a wire for bone plug passage is inserted. The graft with sutures attached to the wires is inserted. Under arthroscopic guide, the posterior part of the graft is fixated using an oblique loop suture $^{44)}$ in an inside-out fashion (Fig. 3C-3D), and the anterior part is fixated using a polydioxanone (PDS) suture in an outsidein fashion. Once graft fixation is confirmed with arthroscopy, the sutures are ligated. 

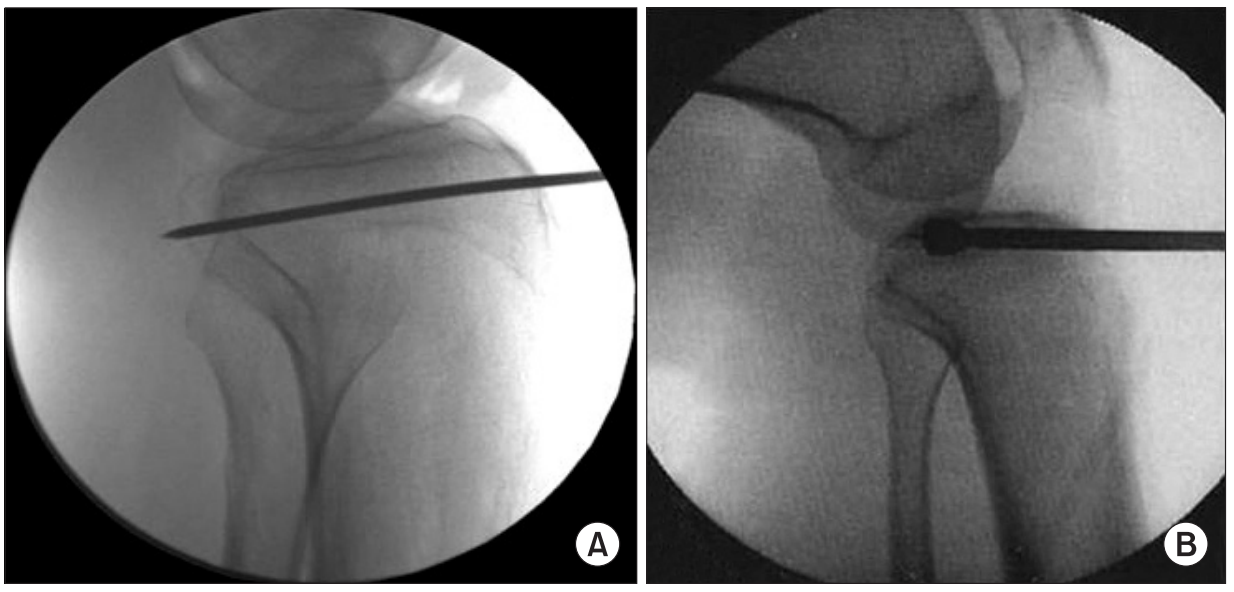

Fig. 4. (A) Insertion of the guide pin paralleled with the tibial slope. (B) The slot position according to the tangential line that connects from the anterior horn to the posterior horn. This is our maneuver.
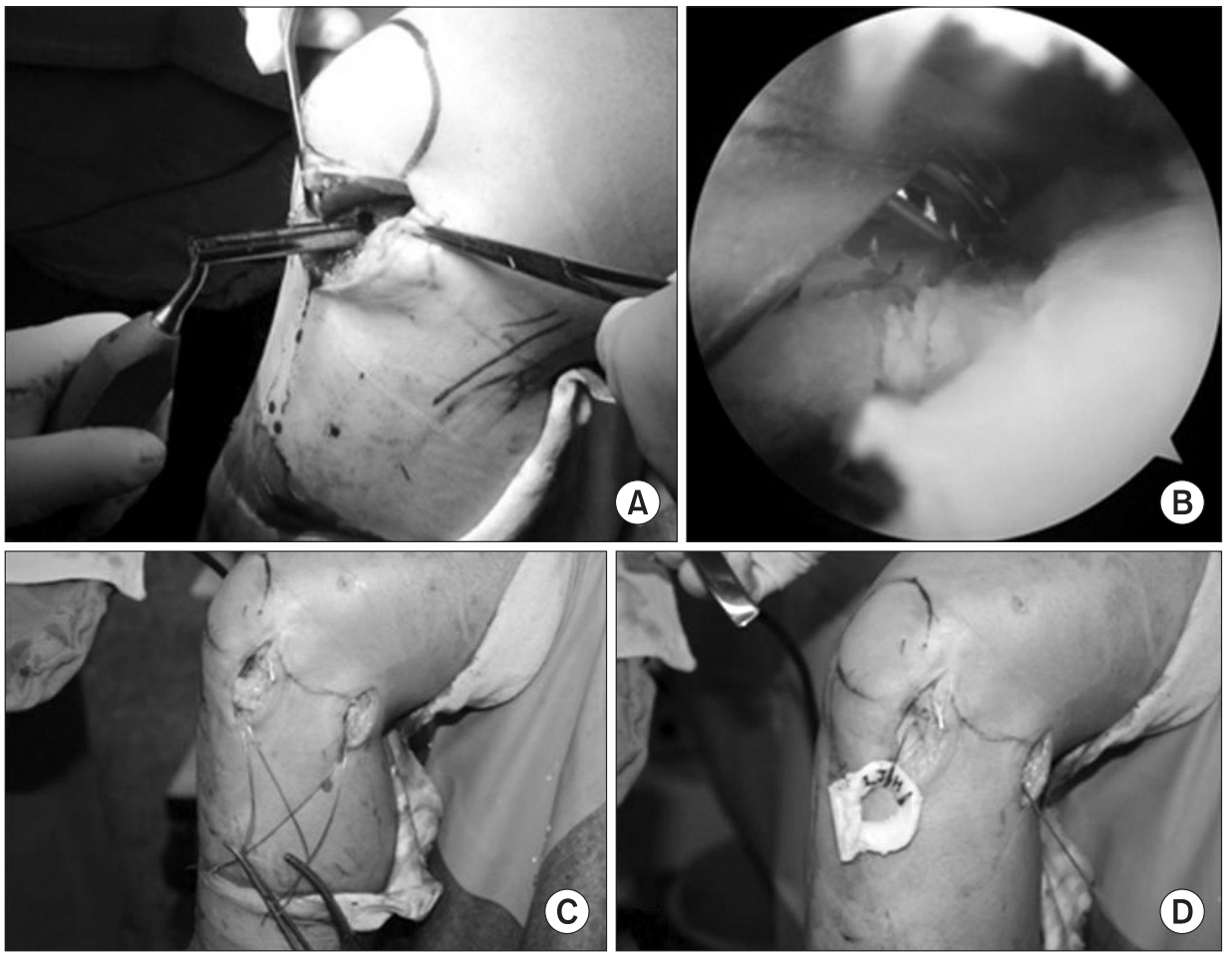

Fig. 5. (A) New device of key-hole technique. (B) Beveling at the tunnel of posterior horn area, by arthroscopy. (C) Insertion of the guide wires. (D) Insertion of the graft with pulling the leading suture.

2) Lateral meniscus transplantation using Key-hole technique The remnant meniscus is removed leaving 1-2 mm of the outer rim. The exact anterior and posterior horn sites are marked using an arthrocare. After an anterior arthrotomy and posterolateral resection, a guide pin is inserted medial to the lateral border of the patellar tendon, distal to the lateral eminence of the tibial articular surface, and approximately $15^{\circ}$ above the tibial slope $e^{45)}$ (Fig. 4). After confirming the guide pin position using $\mathrm{C}$-arm fluoroscopy, a keyhole shaped through is created in the remnant meniscus using a 10-mm reamer (Fig. 5A). Beveling is performed at the tunnel of the posterior horn root under arthroscopic guide
(Fig. 5B) and a guide wire is passed posterolaterally (Fig. 5C). After an anterior arthrotomy, the suture attached to the graft is inserted using the guide wire and pulled out of the articular capsule (Fig. 5D) when the bone bridge is placed in the slot. Fixation of the graft is achieved with an inside-out \& outside-in technique.

\section{Tips and Pitfalls}

1) Medial meniscus transplantation

Bone plug fixation provides higher fixation strength, compared to soft tissue fixation ${ }^{46,47)}$. However, the disadvantages of the 
procedure include that graft insertion through the joint can be difficult if the bone plug at the posterior horn is large, ACL attachment sites can be damaged during tibial tunnel creation, the bone blocks can be destroyed due to the long distance between the anterior and posterior horns, and the graft can be misplaced due to misdirected insertion on the sagittal or coronal plane. Thus, efforts have been made to overcome these problems including reducing the size of the posterior horn bone plug ${ }^{43)}$, using soft tissue fixation only ${ }^{48)}$, and removing medial tibial spine for better visualization and graft passage ${ }^{42,49)}$. The alternative we prefer is a modified bone plug technique ${ }^{43)}$ in which the bony plug at the posterior horn is removed except for the bony shell. This technique is advantageous for bone-to-bone healing and easy graft passage. An additional benefit is that the tibial bone stock can be preserved for concomitant ligament reconstruction procedure because a transtibial tunnel creation is not necessary with this technique.

\section{2) Lateral meniscus transplantation}

The bone tunnel position is of great importance with the bone bridge technique, especially with the key-hole method. A laterally centered tunnel causes graft subluxation as with the case of an oversized graft ${ }^{50)}$, which leads to tibial plateau cartilage damage; whereas a medially centered tunnel causes increased tension as with the case of an undersized graft and can cause damage to the ACL origins during drilling or beveling. Differences in posterior slope measurement can be $7^{\circ}$ on the medial view and $15^{\circ}-17^{\circ}$ on the lateral view ${ }^{51)}$. Accordingly, we make the bone tunnel to be approximately $15^{\circ}$ higher than the posterior tibial slope during a lateral meniscus transplantation. With the key-hole method, care should also be taken to place the tunnel neither laterally nor medially centered and approximately $15^{\circ}$ higher in the sagittal plane than the posterior slope under the guidance of C-arm fluoroscopy during surgery.

\section{Rehabilitation}

There is some lack of consensus on the rehabilitation program after MAT. Most authors recommend early joint exercises and progressive weight bearing to achieve full range of motion (ROM) within 2 months and return to sports activities in 6-9 months ${ }^{13,20,52,53)}$. ROM exercises are administered according to the stage of rehabilitation (Table 2). Closed kinetic chain exercises and patellar mobilization are encouraged. Open kinetic leg curl exercise that creates a suction cup effect is not allowed in the early rehabilitation stage. Proprioception and neuromuscular control exercises are allowed immediately after surgery with a
Table 2. Our Protocol of Rehabilitation

\begin{tabular}{lccc}
\hline \multicolumn{1}{c}{ Postoperative (wk) } & $1-3$ & $3-6$ & $6-9$ \\
\hline Patellar mobilization & $\mathrm{X}$ & & \\
Brace (long leg) & $\mathrm{X}$ & & \\
Range of motion $\left(^{\circ}\right)$ & & & \\
$0-60$ & $\mathrm{X}$ & & $\mathrm{X}$ \\
$0-90$ & & $\mathrm{X}$ & \\
$0-120$ & & & \\
Weight bearing & & & \\
$\quad$ Toe touch-1/4 body weight & $\mathrm{X}$ & $\mathrm{X}$ & \\
1/2 to $3 / 4$ body weight & & & $\mathrm{X}$ \\
Full body weight & & & \\
\hline
\end{tabular}

goal of performing light jogging by 4-6 months postoperatively and sports activities by 6-9 months postoperatively.

\section{Outcomes}

The reported success rates of MAT vary between $12.5-100 \%$ (mean, 60\%). Some studies have shown $85 \%$ of excellent results with the use of improved surgical techniques and aggressive treatment for combined injuries ${ }^{13,15,25,30,52,54-56)}$. Cole et al. ${ }^{57)}$ reported that $77.5 \%$ of the total 39 patients ( 44 cases) were satisfied with transplantation at $\geq 2$ years after surgery. In the study by Stollsteimer et al. ${ }^{15)}$, pain reduction and satisfaction were observed in $78 \%$ of the total 22 patients between 1 to 5 years after surgery. Graf et al. ${ }^{52)}$ found a $75 \%$ satisfaction rate in 8 patients who had undergone meniscus transplantation in conjunction with ACL reconstruction for the mean period of 9.7 years after surgery. Verdonk et al. ${ }^{30)}$ performed 27 cases of medial meniscus transplantation and 15 cases of lateral meniscus transplantation. Even of the medial procedures were associated with a high tibial osteotomy. The patient satisfaction rate was $90 \%$ at $\geq 10$ years after surgery. Kim et al. ${ }^{55)}$ reported that $86.2 \%$ of the 29 cases of isolated lateral MAT were either satisfactory or fair at the mean of 53.6 months after surgery. In our previous study, we performed 15 cases of medial and 21 cases of lateral meniscal allograft transplantation and found that $97.2 \%$ of the 36 patients achieved satisfactory results. Progression of arthritis was not observed at the last follow-up in $77.8 \%$ of the patients in the radiographic assessment using the Kellgren-Lawrence grading system and MRI assessment ${ }^{41}$. However, direct comparison of these studies is difficult due to the differences in the graft preservation method (cryopreserved, fresh frozen, or viable) and surgical technique (with or without bone block, open or arthroscopically assisted).

The possible complications of meniscus transplantation include 
reruptures, graft shrinkage, and extrusion. Graft shrinkage is common with the lyophilized grafts, whereas rare with fresh or fresh frozen grafts. The long-term effects of graft extrusion remain controversial ${ }^{30,41,45)}$.

The ultimate goal of MAT is cartilage protection and its efficacy has not yet been fully investigated. In some animal model studies, meniscus transplantation was more effective in reducing the cartilage degeneration than meniscectomy, albeit not comparable to the intact meniscus ${ }^{58,59)}$. Rijk ${ }^{60)}$ recommended to perform MAT as early as possible to improve the chondroprotective role, whereas Elliott et al. ${ }^{61)}$ reported that the timing of MAT was not significantly correlated with the chondroprotection. Verdonk et $\mathrm{al}^{30}{ }^{30}$ reported that there were no radiographic evidence of joint space narrowing in $41 \%$ of the patients and MRI evidence of progression of arthritis in 35\% of the patients during the $\geq 10$ years of follow-up period. The long-term effects of MAT should be further investigated in future studies. However, it is our understanding that MAT would provide some level of chondroprotection, although it cannot be comparable to the intact meniscus.

\section{Conclusions}

Meniscus transplantation can be a viable option for patients who are $<50$ years of age without knee instability and malalignment following subtotal or total meniscectomy. The short-and mid-term efficacy of the procedure has been reported successful in terms of pain relief and functional improvement. However, there are no established surgical techniques and the available methods are technically challenging. The effect of the procedure on chondroprotection and complications including extrusion should be further investigated in studies involving a long-term follow-up.

\section{References}

1. Fukubayashi T, Kurosawa $\mathrm{H}$. The contact area and pressure distribution pattern of the knee. A study of normal and osteoarthrotic knee joints. Acta Orthop Scand. 1980;51:8719.

2. Henning CE, Lynch MA. Current concepts of meniscal function and pathology. Clin Sports Med. 1985;4:259-65.

3. Kurosawa H, Fukubayashi T, Nakajima H. Load-bearing mode of the knee joint: physical behavior of the knee joint with or without menisci. Clin Orthop Relat Res. 1980;(149):283-90.
4. Renstrom P, Johnson RJ. Anatomy and biomechanics of the menisci. Clin Sports Med. 1990;9:523-38.

5. Voloshin AS, Wosk J. Shock absorption of meniscectomized and painful knees: a comparative in vivo study. J Biomed Eng. 1983;5:157-61.

6. Fairbank TJ. Knee joint changes after meniscectomy. J Bone Joint Surg Br. 1948;30:664-70.

7. Lanzer WL, Komenda G. Changes in articular cartilage after meniscectomy. Clin Orthop Relat Res. 1990;(252):41-8.

8. Cooper DE, Arnoczky SP, Warren RF. Meniscal repair. Clin Sports Med. 1991;10:529-48.

9. Morgan CD, Wojtys EM, Casscells CD, Casscells SW. Arthroscopic meniscal repair evaluated by second-look arthroscopy. Am J Sports Med. 1991;19:632-7.

10. Northmore-Ball MD, Dandy DJ, Jackson RW. Arthroscopic, open partial, and total meniscectomy. A comparative study. J Bone Joint Surg Br. 1983;65:400-4.

11. Milachowski KA, Weismeier K, Wirth CJ. Homologous meniscus transplantation. Experimental and clinical results. Int Orthop. 1989;13:1-11.

12. Rodeo SA. Meniscal allografts: where do we stand? Am J Sports Med. 2001;29:246-61.

13. Rath E, Richmond JC, Yassir W, Albright JD, Gundogan F. Meniscal allograft transplantation. Two- to eight-year results. Am J Sports Med. 2001;29:410-4.

14. Rijk PC. Meniscal allograft transplantation-part I: background, results, graft selection and preservation, and surgical considerations. Arthroscopy. 2004;20:728-43.

15. Stollsteimer GT, Shelton WR, Dukes A, Bomboy AL. Meniscal allograft transplantation: a 1- to 5-year follow-up of 22 patients. Arthroscopy. 2000;16:343-7.

16. Sekiya JK, Ellingson CI. Meniscal allograft transplantation. J Am Acad Orthop Surg. 2006;14:164-74.

17. Cole BJ, Carter TR, Rodeo SA. Allograft meniscal transplantation: background, techniques, and results. Instr Course Lect. 2003;52:383-96.

18. Matava MJ. Meniscal allograft transplantation: a systematic review. Clin Orthop Relat Res. 2007;455:142-57.

19. van Arkel ER, de Boer HH. Human meniscal transplantation. Preliminary results at 2 to 5 -year follow-up. J Bone Joint Surg Br. 1995;77:589-95.

20. Noyes FR, Barber-Westin SD, Rankin M. Meniscal transplantation in symptomatic patients less than fifty years old. J Bone Joint Surg Am. 2004;86-A:1392-404.

21. Cameron JC, Saha S. Meniscal allograft transplantation for unicompartmental arthritis of the knee. Clin Orthop Relat 
Res. 1997;(337):164-71.

22. Sekiya JK, Giffin JR, Irrgang JJ, Fu FH, Harner CD. Clinical outcomes after combined meniscal allograft transplantation and anterior cruciate ligament reconstruction. Am J Sports Med. 2003;31:896-906.

23. Verdonk PC, Demurie A, Almqvist KF, Veys EM, Verbruggen G, Verdonk R. Transplantation of viable meniscal allograft. Survivorship analysis and clinical outcome of one hundred cases. J Bone Joint Surg Am. 2005;87:715-24.

24. Yoldas EA, Sekiya JK, Irrgang JJ, Fu FH, Harner CD. Arthroscopically assisted meniscal allograft transplantation with and without combined anterior cruciate ligament reconstruction. Knee Surg Sports Traumatol Arthrosc. 2003;11:173-82.

25. Rue JP, Yanke AB, Busam ML, McNickle AG, Cole BJ. Prospective evaluation of concurrent meniscus transplantation and articular cartilage repair: minimum 2-year follow-up. Am J Sports Med. 2008;36:1770-8.

26. Farr J, Rawal A, Marberry KM. Concomitant meniscal allograft transplantation and autologous chondrocyte implantation: minimum 2-year follow-up. Am J Sports Med. 2007;35:1459-66.

27. Papageorgiou CD, Gil JE, Kanamori A, Fenwick JA, Woo $\mathrm{SL}, \mathrm{Fu} \mathrm{FH}$. The biomechanical interdependence between the anterior cruciate ligament replacement graft and the medial meniscus. Am J Sports Med. 2001;29:226-31.

28. Noyes FR, Barber-Westin SD. Meniscus transplantation: indications, techniques, clinical outcomes. Instr Course Lect. 2005;54:341-53.

29. Noyes FR, Barber-Westin SD. Prospective evaluation of allograft meniscus transplantation: a minimum 2-year follow-up. Am J Sports Med. 2006;34:2038-9.

30. Verdonk PC, Verstraete KL, Almqvist KF, De Cuyper K, Veys EM, Verbruggen G, Verdonk R. Meniscal allograft transplantation: long-term clinical results with radiological and magnetic resonance imaging correlations. Knee Surg Sports Traumatol Arthrosc. 2006;14:694-706.

31. Farr J, Gersoff W. Current meniscal allograft transplantation. Sports Med Arthrosc. 2004;12:69-82.

32. Noyes FR, Barber-Westin SD. Repair of complex and avascular meniscal tears and meniscal transplantation. J Bone Joint Surg Am. 2010;92:1012-29.

33. Rodeo SA, Seneviratne A, Suzuki K, Felker K, Wickiewicz TL, Warren RF. Histological analysis of human meniscal allografts. A preliminary report. J Bone Joint Surg Am.
2000;82:1071-82.

34. Caldwell PE 3rd, Shelton WR. Indications for allografts. Orthop Clin North Am. 2005;36:459-67.

35. Yahia L, Zukor D. Irradiated meniscal allotransplants of rabbits: study of the mechanical properties at six months postoperation. Acta Orthop Belg. 1994;60:210-5.

36. Pollard ME, Kang Q, Berg EE. Radiographic sizing for meniscal transplantation. Arthroscopy. 1995;11:684-7.

37. Shaffer B, Kennedy S, Klimkiewicz J, Yao L. Preoperative sizing of meniscal allografts in meniscus transplantation. Am J Sports Med. 2000;28:524-33.

38. Wilcox TR, Goble EM, Doucette SA. Goble technique of meniscus transplantation. Am J Knee Surg. 1996;9:37-42.

39. Dienst M, Greis PE, Ellis BJ, Bachus KN, Burks RT. Effect of lateral meniscal allograft sizing on contact mechanics of the lateral tibial plateau: an experimental study in human cadaveric knee joints. Am J Sports Med. 2007;35:34-42.

40. McDermott ID, Sharifi F, Bull AM, Gupte CM, Thomas RW, Amis AA. An anatomical study of meniscal allograft sizing. Knee Surg Sports Traumatol Arthrosc. 2004;12:130-5.

41. Jang SH, Kim JG, Ha JG, Shim JC. Reducing the size of the meniscal allograft decreases the percentage of extrusion after meniscal allograft transplantation. Arthroscopy. 2011;27:914-22.

42. Alhalki MM, Howell SM, Hull ML. How three methods for fixing a medial meniscal autograft affect tibial contact mechanics. Am J Sports Med. 1999;27:320-8.

43. Kim JG, Lee YS, Lee SW, Kim YJ, Kong DH, Ko MS. Arthroscopically assisted medial meniscal allograft transplantation using a modified bone plug to facilitate passage: surgical technique. J Knee Surg. 2009;22:259-63.

44. Kocabey Y, Taser O, Nyland J, Doral MN, Demirhan M, Caborn DN, Sarban S. Pullout strength of meniscal repair after cyclic loading: comparison of vertical, horizontal, and oblique suture techniques. Knee Surg Sports Traumatol Arthrosc. 2006;14:998-1003.

45. Lee DH, Kim SB, Kim TH, Cha EJ, Bin SI. Midterm outcomes after meniscal allograft transplantation: comparison of cases with extrusion versus without extrusion. Am J Sports Med. 2010;38:247-54.

46. Chen MI, Branch TP, Hutton WC. Is it important to secure the hems during lateral meniscal transplantation? A cadaveric study. Arthroscopy. 1996;12:174-81.

47. Alhalki MM, Hull ML, Howell SM. Contact mechanics of the medial tibial plateau after implantation of a medial meniscal allograft. A human cadaveric study. Am J Sports 
Med. 2000;28:370-6.

48. Verdonk PC, Demurie A, Almqvist KF, Veys EM, Verbruggen G, Verdonk R. Transplantation of viable meniscal allograft. Surgical technique. J Bone Joint Surg Am. 2006;88 Suppl 1 Pt 1:109-18.

49. Goble EM, Verdonk R, Kohn D. Arthroscopic and open surgical techniques for meniscus replacement: meniscal allograft transplantation and tendon autograft transplantation. Scand J Med Sci Sports. 1999;9:168-76.

50. Jung YH, Choi NH, Victoroff BN. Arthroscopic stabilization of the lateral capsule of the knee in meniscal transplantation. Knee Surg Sports Traumatol Arthrosc. 2011;19:189-91.

51. Lee YS, Kim JG, Lim HC, Park JH, Park JW. The relationship between tibial slope and meniscal insertion. Knee Surg Sports Traumatol Arthrosc. 2009;17:1416-20.

52. Graf KW Jr, Sekiya JK, Wojtys EM; Department of Orthopaedic Surgery, University of Michigan Medical Center, Ann Arbor, Michigan, USA. Long-term results after combined medial meniscal allograft transplantation and anterior cruciate ligament reconstruction: minimum 8.5-year followup study. Arthroscopy. 2004;20:129-40.

53. Ryu RK, Dunbar VW, Morse GG. Meniscal allograft replacement: a 1-year to 6-year experience. Arthroscopy. 2002;18:989-94.

54. Hergan D, Thut D, Sherman O, Day MS. Meniscal allograft transplantation. Arthroscopy. 2011;27:101-12.

55. Kim CW, Kim JM, Lee SH, Kim JH, Huang J, Kim KA,
Bin SI. Results of isolated lateral meniscus allograft transplantation: focus on objective evaluations with magnetic resonance imaging. Am J Sports Med. 2011;39:1960-7.

56. Ha JK, Shim JC, Kim DW, Lee YS, Ra HJ, Kim JG. Relationship between meniscal extrusion and various clinical findings after meniscus allograft transplantation. Am J Sports Med. 2010;38:2448-55.

57. Cole BJ, Dennis MG, Lee SJ, Nho SJ, Kalsi RS, Hayden JK, Verma NN. Prospective evaluation of allograft meniscus transplantation: a minimum 2-year follow-up. Am J Sports Med. 2006;34:919-27.

58. Kelly BT, Potter HG, Deng XH, Pearle AD, Turner AS, Warren RF, Rodeo SA. Meniscal allograft transplantation in the sheep knee: evaluation of chondroprotective effects. Am J Sports Med. 2006;34:1464-77.

59. Szomor ZL, Fermanis G, Murrell GA. Scapulothoracic fusion for a stroke patient with Achilles tendon allograft. J Shoulder Elbow Surg. 2000;9:342-3.

60. Rijk PC. Meniscal allograft transplantation-part II: alternative treatments, effects on articular cartilage, and future directions. Arthroscopy. 2004;20:851-9.

61. Elliott DM, Jones R 3rd, Setton LA, Scully SP, Vail TP, Guilak F. Joint degeneration following meniscal allograft transplantation in a canine model: mechanical properties and semiquantitative histology of articular cartilage. Knee Surg Sports Traumatol Arthrosc. 2002;10:109-18. 